\title{
El sentido original de la constructio cartesiana
}

Luis Antonio Velasco Guzmán

Facultad de Estudios Superiores Acatlán-UNAM

\section{Resumen}

Este breve artículo es un intento por aclarar la importancia que el concepto cartesiano de construcción tiene para su proyecto filosófico. Para desarrollar esta idea presentaré, en primer lugar, cómo entiendo la paradoja moderna respecto de la construcción del mundo y aclararé el sentido que se le daba al concepto de constructio antes de la innovación cartesiana. Después, analizaré los paradigmas cartesianos de construcción a través del proceso que delimito con los dos ciclos de construcción —indispensables para la creación del mundo moderno. Este análisis sigue muy de cerca el argumento del Discurso del método sobre lo que su autor propone en relación con la construcción del mundo.

Palabras clave: construcción del mundo, paradigmas cartesianos de construcción, modernidad.

\section{Abstract}

This paper intends to clarify the relevance of the Cartesian concept of construction for his main philosophical project. The via to develop this idea is divided in two terms: first, I will explain my understanding of the modern paradox about the construction of the world and then I will clarify the 
sense given to the concept of constructio before the Cartesian new sense. Afterwards, I will study the Cartesian paradigms of construction through the process which I call the two Cartesian Construction Cycles — which are needed for the creation of the modern world. This part of my paper intends to be a careful reading of the argument in the Discourse on the Method which develops the Cartesian question on the new world's construction proposed by Descartes.

Keywords: world's construction, Cartesian paradigms, Modernity.

\section{Introducción}

R ené Descartes es considerado, de manera unánime y sin exa-geraciones, el padre de la filosofía moderna. La modernidad filosófica puede ser entendida como el desarrollo del nuevo modo del pensar inaugurado por Descartes, tanto como los resultados ulteriores de dicha innovación. Descartes, así entendido, es el autor por antonomasia. Ahora bien, todo autor crea, y en este caso su creación está supeditada a su innovador proyecto filosófico, mas ¡en qué radica éste?, ¿en qué consiste el proyecto filosófico original del creador Descartes?, éstas son las preguntas que orientarán, como contexto general, el estudio que presento a continuación. Sin embargo, aún se puede acotar más el propósito del presente texto, y es que con éste espero mostrar la importancia del radicalmente nuevo sentido original de la construcción cartesiana.

Para anticipar la importancia de la noción cartesiana de construcción podemos advertir en este momento que es la que hace posible la comprensión del nuevo mundo, del mundo moderno —razón por la cual aceptamos la opinión común de que Descartes es el padre de la nueva época. Su noción de construcción es la que da forma y contenido al nuevo mundo. Para desarrollar estas ideas, primero, presentaré la paradoja inherente a la autocomprensión del hombre mo- 
derno en conexión con la noción de construcción del hombre premoderno (o para decirlo con más claridad, precartesiano). Después, delimitaré, mediante un análisis casi lineal del Discurso del método, lo que el autor de la nueva vía para entender los problemas añejos de la tradición filosófica inaugura con su innovadora manera de concebir la cuestión de la construcción. En este contexto, será preciso delimitar los casos ejemplares con los que Descartes ilumina la importancia del acto constructor. Me valgo de una imagen para ofrecer de forma sinóptica esta idea (Esquema A). A estos casos ejemplares, que el discurso cartesiano dedica un orden especial, les hemos denominado paradigmas de la construcción del mundo moderno y descubrimos, mediante su análisis, un orden ascendente en el proceso de dicha construcción. Este orden lleva al hombre de su imperfección natural a su perfección, constatada con la construcción del mundo moderno -en contraste con el mundo antiguo. Me valgo de otra imagen con la misma finalidad en este nuevo contexto (Esquema B). El lector generoso encontrará el orden, casi matemático, de este ascenso, denotando en los dos ciclos del proceso de la construcción del mundo moderno y podra ver su importancia a la luz de la develación del movimiento de dichos ciclos. Si bien éstos son necesarios en el proceso de construcción del mundo moderno, los detalles son problemáticos. El que requiere de una mención especial en esta introducción es el de los paradigmas de construcción cartesiana, que trabaja con los casos de los diversos tipos de legisladores, así como el que desarrolla la noción del nuevo hombre que construye el nuevo mundo. La exposición de todo esto se encuentra en las páginas siguientes.

El hecho de haberme abocado a la búsqueda del problema de la construcción del mundo moderno con un estudio sobre el Discurso del método y dejar de lado, ya no digamos el análisis, sino la mera mención de las obras, por ejemplo, de filosofía natural del enorme corpus cartesiano, encuentra su justificación en el hecho de que Des- 
cartes siempre consideró esta obra como la introducción a su sistema. Al ser el Discurso una obra introductoria, me parece, nos permite acercarnos con mayor seguridad a las profundidades del vasto océano cartesiano sin sucumbir en el desmesurado intento por abarcar más de lo que nuestras fuerzas y espacio nos permite. Así entendidas las cosas, como resulta evidente, éste también es un estudio introductorio.

\section{La paradoja fundamental del hombre moderno y la antigua constructio}

El hombre moderno tiene la convicción de ser su propio creador, aunque tal pretensión resulta problemática al enfrentar el hecho de que, pese a sus afanes, no puede cancelar su naturaleza finita. El proyecto de la Modernidad (el método y la construcción del mundo modernos), desde sus orígenes, apunta con todos sus recursos antinaturales a cancelar por cualquier medio posible la innegable naturaleza finita del hombre. Parece que el resultado de la pretensión moderna del hombre por ser su propio creador es una hybris a la naturaleza finita del hombre. El dilema de esta hybris puede plantearse en los siguientes términos: o bien el hombre tiene un origen fuera de sí o él es su propio origen.

Estos dos caminos son dilemáticos, no sólo por la diferencia de las vías entre lo trascendente y lo inmanente sino, sobre todo, por lo

* Mi profunda gratitud a la generosidad de colegas y amigos, sin cuya orientación, conversaciones y obras, ésta no hubiera llegado a ser la versión que me permito presentar al público. Agradezco en especial Laura Benítez (IIF-UNAM), Mauricio Beuchot (IIF-UNAM), Carlos Pereda (IIF-UNAM), Antonio Marino (FES AcatlánUNAM) y Juan Moreno (UAQ). También, mi absoluto reconocimiento a los lectores ciegos de la versión anterior porque en mi caso su anónima ayuda favoreció en gran medida a la mejoría y claridad de mi pensamiento. Por último, a la Universidad de Guanajuato por su cuidado de la vida de las ideas en el contexto de la academia. 
que se deriva de estas dos comprensiones de la realidad. En el caso de la vía trascendente, la finitud del hombre es acorde con el devenir natural o con los designios de Dios. En cambio, en el caso de la vía inmanente, la finitud humana es considerada como la molestia más apremiante a superar. Estas dos vías, no obstante, poseen otra característica que las presenta como dilemáticas: la cuestión de la felicidad. Ésta es la que marca la diferencia esencial entre una y otra vía. En el caso de la trascendencia, la finitud humana, si bien compleja y problemática para la perspectiva del hombre, es al final aceptable en su propia constitución, pues evidencia un orden (natural o divino) al que el hombre pertenece y que, en lo general, estaría dispuesto a aceptar; más aún, de su aceptación depende su posibilidad de ocupar el lugar que le corresponde en el cosmos —eminentemente natural — o su posibilidad de obtener la redención —eminentemente divina - a través de la salvación del alma después de la muerte. En el caso de la inmanencia, como todo mundo sabe, la cuestión de la felicidad no depende en absoluto ni de Dios ni de la naturaleza, sino sólo del hombre mismo, y aunque esta versión moderna de la felicidad es la que impera hoy en día, resultaría ventajoso reflexionar sobre sus fundamentos.

La autocomprensión del hombre moderno conduce a una situación paradójica: desear ser el propio principio, tanto como llegar a ser Dios sin poder dejar de ser mortal, es la condición que ofrece la naturaleza humana al ejercicio de la construcción del hombre moderno. Esta paradoja sustentada en el deseo ilimitado del hombre moderno por llegar a ser su propio principio se torna peculiarmente más explícita al rastrear el uso del término construcción, con el cual los modernos emparentaron su acción a la del dios creador. En su uso premoderno, el término constructio denotaba un sentido estilístico u oratorio y se empleaba para llamar la atención al "hacer una conexión" de palabras o frases en un discurso y, aún cuando el verbo 
construere podía ser empleado para señalar a la acción de hacer o fabricar en general, el tropo preferido para poner en conexión un discurso era exaedificatio. ${ }^{1}$ Constructio es empleado desde la antigüedad tardía hasta el medievo como un término gramatical; alude en específico a la congruencia sintáctica de los casos entre los sustantivos y los adjetivos, entre los sujetos y los verbos, etc. Abundan pruebas que evidencian la aceptación de que el término latino constructio es el equivalente del griego sintaxis. ${ }^{2}$

Cómo es posible que el uso retórico y gramatical de construcción realice su metamorfosis al nuevo sentido técnico y matemático de la modernidad, es una cuestión en la que la presente exposición no se detendrá a indagar, sobre todo, cuando existen inmejorables explicaciones del caso. ${ }^{3}$ Sin embargo sí es necesario hacer patente la nueva comprensión del concepto construcción, sobre todo, para los fundadores del pensamiento moderno y las implicaciones teóricas más importantes que de estos planteamientos se derivan.

Sin lugar a dudas, el mero uso gramatical del término constructio llegó a su fin en la Modernidad —en particular con Descartes y Hobbes. En sus discursos, construcción y su nuevo sentido urden la trama que dará cabida a los nuevos tejidos de una época que se considera radicalmente distinta a la anterior. En esta nueva época existen algunas nociones básicas que la distinguen de las pasadas (las ideas que más destacan son las de ciencia, progreso y método, to-

${ }^{1}$ Cfr. Cicerón, Brutus, 78.272; De inventione, 20.72 y De oratore, 2.15; 2.37.

2 Resulta en especial interesante descubrir que el uso antiguo del término griego syntaxis denotaba, en la mayoría de sus acepciones, el sentido gramatical que se está explicando. Y cabe señalar que el único sentido matemático con el que este término fue empleado aparece en el título original del Almagesto, de Ptolomeo. (Cfr. Lachterman, 1989: 207). Por otro lado, en el opúsculo Sobre la lengua vulgar, Dante (1987: 768) también comparte el sentido gramatical del término constructio que tratamos de evidenciar como el uso premoderno de dicha noción.

${ }^{3}$ Cfr. Lachterman (1989: 50-61 y 207-209); asimismo, Klein (1992: 178-85). 
das ellas decididamente relacionadas). Resta aclarar, sin embargo, de dónde proceden estas nociones y cuál es el presupuesto sobre el que se sustentan. Tales cuestiones son las que trataré de esclarecer con un análisis sobre la importancia y el sentido de la construcción en Descartes. Por tratarse de un análisis muy preciso, cuya finalidad es la de explicitar el sentido diferente al meramente gramatical que en la Antigüedad se le daba al término constructio, me abocaré directamente a los pasajes del Discurso del método en los que su autor manifiesta el nuevo sentido que se le habrá de otorgar a dicho concepto.

En la primera parte del Discurso del método Descartes realiza de forma pública el escrutinio de las ciencias o disciplinas antiguas siguiendo el criterio de utilidad aprendido de sus maestros jesuitas y que él mismo caracterizó al explicar que "el estudio le daría un conocimiento claro y seguro de lo que es útil a la vida". La lista de ciencias "inútiles", como sabemos, es amplia: lo que se estudia en las escuelas, las lenguas, las fábulas, la historia, la literatura, la elocuencia, la poesía, el estudio de las costumbres, la teología, la filosofía, la jurisprudencia, la alquimia, la astrología. La única que exceptúa en este catálogo (AT, VI: 1-11) es la matemática, no sin una observación importante: le asombró que "no se hubiera edificado [bâti] algo de mayor relevancia sobre fundamentos tan firmes y sólidos". ${ }^{4}$ Esta observación, en apariencia ingenua, es vital para el desarrollo

${ }^{4}$ Confrontar la primera parte del Discurso del método, que desarrolla las consideraciones relativas a las ciencias, donde Descartes hace énfasis en el carácter práctico o útil del conocimiento que está proponiendo. Por ejemplo, comienza postulando que el bon sens o razón es aquello que está mejor distribuido entre los hombres, pero su importancia radica en la utilidad que la propia razón puede otorgar al hombre moderno: "Je me plaisais surtout aux Mathematiques, à cause de la certitude et de l'évidence de leurs raisons; mais je ne remarquais point encore leur vrai usage, et, pensant qu'elles ne servaient qu'aux Arts Mécaniques, je m'etonnais de ce que, leurs fondements étant si fermes et si solides, on n'avait rien bâti dessus de plus relevé" (AT, VI: 7). Las cursivas son mías. 
del proyecto cartesiano porque, como sabemos por la segunda parte del Discurso, su método proviene de esos fundamentos "tan firmes y sólidos". Es decir, a sus propios ojos está realizando lo que toda la tradición matemática (léase, científica) no logró. Él sí se percató, más allá del servicio que las matemáticas proveen a la mecánica, del uso real de las matemáticas, el cual consistía no tanto en poner de manifiesto un buen espíritu mediante el entendimiento correcto de sus principios sino, sobre todo, en aplicar bien ese espíritu (Cfr. AT, VI: 2); es decir, en darle cabida al método y ejecutarlo. Esta misma observación cartesiana es importante para nuestra investigación por ser ésta la primera ocasión en la que Descartes le permite a su lector percatarse de su sentido innovador y de su importancia en el proyecto moderno - eminentemente constructor.

Cuando Descartes se asombra de que una edificación superior no se hubiera erigido ya sobre el desarrollo y uso práctico de las matemáticas está empleando el verbo preciso: bâtir. Con él alude al ejercicio y a la acción de la construcción y la edificación, es decir, al nuevo sentido que inaugura para la comprensión de la noción de construcción en la nueva época, su época. El sentido moderno de este concepto está señalando un nuevo modo de entender la relación entre la obra y el operante (¿artífice?), y esto es algo que se puede apreciar al reflexionar sobre los siete tipos de constructores que Descartes propone para explicar su innovador proyecto filosófico, sustentado en la noción de construcción; veamos cuáles son y a qué aluden.

\section{Los paradigmas cartesianos de construcción}

La segunda parte del Discurso del Método (AT, VI: 11-22) es la sección conocida por la presentación de "las partes del método". Allí es donde Descartes evidencia su preocupación por la perfección de las cosas que se hacen con la intervención de muchas partes; es decir, de las "obras compuestas de varias piezas" — utilizando las palabras del 
autor. Su método para investigar la verdad es una obra compuesta de varias partes y su presentación parece justificarse en los ejemplos de construcciones aducidos en su discurso. Lo que nos permite "ver" estos ejemplos es la importancia paradigmática de cómo una obra que pertenece a un solo autor puede garantizar su perfección. El orden en que estos paradigmas de construcción son presentados por Descartes nos orienta respecto del grado de perfeccionamiento de su obra. Tal como lo afirma Descartes, "las obras compuestas de varias piezas y hechas por varias personas no son tan perfectas como las ejecutadas por una sola persona" (AT, VI: 11), es la clave para comprender sus siete casos ejemplares de constructores, paradigmas de construcción, que mientan un ascenso evidente en la complejidad de la obra y especialización del constructor:

1. El único arquitecto de un edificio.

2. El único ingeniero de una ciudad.

3. El caso abstracto del único legislador "prudente" que da leyes a un pueblo.

4. El caso especial del único legislador divino, Dios, quien hizo las leyes del estado de la verdadera religión, que debe ser incomparablemente mejor regulado que todas las otras.

5. El caso concreto del único legislador humano de la pagana Esparta.

6. Los razonamientos sencillos hechos con naturalidad por un solo hombre de "buen sentido" (bon sens).

7. El caso hipotético y final de un solo hombre que daba un uso perfecto a su razón sin ninguna ayuda desde su infancia, no afectado por apetitos ni preceptores.

Para ayudarme a explicar la estructura de la presentación cartesiana acerca de los paradigmas de construcción y su elevación en el grado de perfección, guiaré mi interpretación con el Esquema A (ver infra p. 172): del lado izquierdo numerados, los paradigmas cartesia- 
nos de construcción; del derecho y a contraespejo, mi interpretación de los primeros.

Los paradigmas cartesianos de construcción son presentados de manera puntual por su autor tal como los enumeré arriba. De acuerdo con el orden cartesiano se observa un ascenso, no sólo en lo concerniente a la complejidad y perfección de lo que implica cada paradigma (por ejemplo, construir ciudades es más complejo que construir edificios, así como crear leyes es más complejo y requiere de mayor perfección que la construcción del plano de una ciudad, etc.), sino, sobre todo, en la importancia del séptimo y último paradigma de perfección (i.e., el hombre cartesiano), pues como lo mostraré a continuación, este paradigma es el constructor definitivo del nuevo mundo.

Descartes nos explica cómo tenemos que entender cada uno de estos paradigmas de construcción cuando afirma que "no hay tanta perfección en las obras compuestas [composés] de muchas partes y producidas por varios artífices diferentes como en las obras de un solo hombre", me parece pertinente señalar que debemos considerar esta afirmación como advertencia y clave para interpretar de manera correcta su proyecto filosófico. Así, si atendemos al primer paradigma de construcción que nuestro autor nos ofrece, el del único arquitecto de un edificio, tenemos que entender por qué es mejor que un solo arquitecto sea quien proyecte un edificio (obra compuesta de varias partes) a que dicho proyecto lo realicen varios de ellos. La razón cartesiana de este primer paradigma es que un edificio cuyo proyecto proviene de un solo arquitecto es más atractivo y mejor planeado. Podemos entender esto cuando vemos que un proyecto arquitectónico que no requiere de una segunda revisión y modificación de su presentación inicial es porque, de hecho, en su origen, ha sido planeado de forma correcta. En sentido estricto, que un proyecto arquitectónico sea más atractivo es algo colateral a la correcta planeación, pues este juicio 
estético depende de que en dicho proyecto se hagan coincidir todas las partes de la obra hacia una sola meta e interés arquitectónicos. Esa coincidencia de las partes sólo puede ser concordante si la estructura sigue un único plan, lo cual garantiza que el proyecto no es confuso. Las inconsistencias estéticas son producto de la mezcla de intereses, metas y estilos que no pueden unirse sin que esto resulte en una catástrofe estética y arquitectónica.

El segundo paradigma de construcción es el de las ciudades. Como es evidente, estamos frente a un paradigma más complejo que el anterior por lo que la fuerza de la razón para propiciar el orden en la construcción habrá de ser mayor. La construcción de una ciudad requiere no sólo del conocimiento preciso para levantar edificios, lo cual ya es complejo, sino de una serie inenarrable de detalles (edificios públicos, hogares para los ciudadanos, orientación de las calles y vialidades, definición estratégica de lugares públicos, abastecimiento de agua, resguardo en caso de peligro, etc.). Además requiere de una planeación tan amplia que abarque hasta el posible crecimiento de la comunidad. Descartes nos hace ver que las ciudades antiguas normalmente encontraban su origen en la expansión de los caseríos a las villas y que de manera posterior y paulatina iban transformándose en las ciudades que ahora conocemos. Éstas son mucho más irregulares que las poblaciones que eran creadas con una exigencia impuesta o siguiendo un fin más o menos importante para los integrantes de esa comunidad. Debido a ello, en ocasiones, la construcción de dicha ciudad se realizaba de forma rápida con los esfuerzos armonizados de una sola generación. Este tipo de observación, a pesar de su exageración (que se construya una ciudad entera en una sola generación), puede ser aceptada. Pero justo por llamar nuestra atención debemos ser más precavidos. Parece que lo más relevante en el discurso cartesiano respecto de este paradigma no es la brevedad de tiempo en el que se puede construir una ciudad, sino la enunciación final con la 
que nuestro autor compara a estos dos tipos de ciudades. Así, dice que las calles de las ciudades que fueron construidas siguiendo un plan son más simétricas y trazadas con arreglo a ese plan, mientras que las calles de las ciudades que no fueron construidas así son mucho más tortuosas y desiguales. De esta forma, deja de manifiesto que lo que dirigió su construcción fue "más la fortuna que la voluntad de los hombres que usan la razón" (AT, VI: 12). Esta indicación es muy importante porque manifiesta el interés del proyecto moderno cartesiano: se trata de realizar una construcción que evidencie los alcances programados de la razón humana. Nada que sea humano (en este nuevo sentido de lo humano) puede depender del azar y la casualidad. Es decir, que con el proyecto moderno cartesiano el imperio de la fortuna (Fortuna, diosa que dirigió en gran medida los asuntos humanos en el periodo clásico y aún en el renacentista) llegó a su fin... y con él, el inicio de una nueva época. ¿En qué basa Cartesio esta nueva época y a qué conduce?

La respuesta a esta pregunta se encuentra en los paradigmas sexto y séptimo. No obstante, para llegar a ellos se tiene que pasar por los tres centrales, a saber: el legislador ideal, Dios y el legislador real. Éstos apuntan de forma directa y abierta hacia la importancia del método. ${ }^{5}$

${ }^{5}$ También, desde un plano esotérico, encuentro cierta afinidad con el planteamiento cartesiano del problema político. En parte, por la insistente evidencia semántica del término empleado por Descartes para desarrollar esta parte de su discurso ("el que hace leyes" o "legislador", "legislador prudente" o "Dios"). Pero también por su ubicación central en el conjunto de este argumento. Dicha ubicación denota, no sólo un orden en el entramado cartesiano, sino una sugerencia para el lector cuidadoso (i.e., los capítulos centrales de una obra son centrales por su importancia al interior del conjunto de la misma). Por ello, este fragmento cartesiano puede sugerir una revelación importante del planteamiento político de este autor. Aunque esto, si bien es algo que no ha sido estudiado entre los eruditos de Descartes no significa que carezca de importancia. Sin embargo, en esta ocasión, es algo que está fuera de los alcances de este estudio. Una observación final a esta nota: tanto en la 
Su discurso es en apariencia sencillo, ya que "sigue" la misma finalidad y desarrolla la misma idea que en los dos paradigmas de construcción anteriores (edificio y ciudad), sólo que lleva la atención hacia lo que sería el quid del paradigma anterior más complejo (la ciudad). Esto se debe a que una ciudad no puede serlo sin aquello que la determina, organiza, gobierna y la constituye como lo que es, sus leyes. Descartes ofrece la explicación de cómo los pueblos se van civilizando de forma paulatina. Así, hay pueblos que hacen sus leyes de acuerdo con las necesidades que van surgiendo en su desarrollo histórico (tales como crímenes y pleitos civiles). Éstos no tienen, desde un punto de vista político, un sustento sólido ni tan bien organizado como el de aquellos pueblos que desde el principio de su historia decidieron en una asamblea pública observar las leyes que un (solo) prudente legislador les dictara. Inmediatamente después, y como si fuera parte del mismo argumento, nos dice que tal es el caso de "la verdadera religión, en la cual Dios sólo ha hecho las ordenanzas, [por lo que] deben ser incomparablemente mejor reguladas que todas las otras [religiones]" (AT, VI: 12).

En este punto, es preciso hacer una breve reflexión en torno a la relación entre la legislación y la religión, a la cual el argumento cartesiano ha orientado la atención de sus lectores. La tradición de la filosofía política reconoce esta singular cuestión con el nombre de problema teológico-político y es tan complejo que no se trata de exponer aquí su desarrollo completo, ni de ampliar la disputa en torno al problema filosófico de la ley o de Dios, como tampoco de agotar la temática respecto de la diferencia entre la postura clásica (Platón o Aristóteles) y la moderna (Maquiavelo o Spinoza) en relación con este problema. La pretensión es mucho más modesta, se trata de no pasar

filosofía política clásica (Platón y Aristóteles) como en los estudios maquiavélicos sobre este problema, la relación entre teología y política es fundamental para la conformación de la comunidad política. 
inadvertido el hecho de que en el discurso cartesiano el problema teológico-político también ocupa un lugar central en lo que respecta a sus paradigmas de construcción del nuevo mundo, el moderno.

En su argumento, Descartes permite ver el orden y el entretejido de la cuestión teológico-política al imbricar los temas del legislador ideal, de Dios y del legislador real en el orden de su presentación de los tres paradigmas centrales. Resulta evidente que el problema central es el teológico, mas para llegar a él, se tienen que conocer los dos flancos que lo (res-)guardan perfectamente; a saber, el de los legisladores (ideal y real). En esta primera aproximación al problema teológico-político pareciera que Descartes acepta la postura tradicional respecto de la necesidad e importancia de Dios y de la ley en relación con la construcción de un nuevo mundo. Sería muy precipitado en este momento resolver en qué consiste la posición cartesiana. Descartes señala que "ve" que el paradigma central, el de Dios, es demasiado elevado para su público efímero, o sea, para un público no divino, un público no tan elevado. Esta es la razón por la que se puede entender que la elevación del tema tratado ha llegado a su nivel más alto. Sin embargo, el desarrollo de su discurso no se detiene aquí. Inmediatamente después indica que "y para hablar de cosas humanas" insertando el caso histórico real de Esparta, con lo cual muestra su genuina preocupación inmanentista y, al mismo tiempo, encuentra el caso histórico con el que evidencia lo que deseaba probar desde un principio, que la perfección de una obra, como una ciudad bien organizada desde sus orígenes, debe su virtud no a la bondad de cada una de sus leyes, sino a que todas ellas fueron dictadas por un solo legislador. Leyes dictadas por un solo legislador siguen un único fin. Esto sólo es posible mediante el esfuerzo razonado de un único constructor.

Resulta poco probable que Descartes quisiera abandonar allí el problema teológico-político, pues estos tres paradigmas de construcciones (el del legislador ideal, el de Dios que dicta las leyes de 
la verdadera religión y el del legislador real) apuntan más al modo de acción que al resultado de la acción de cada uno de estos actores -incluido Dios. Cada uno de estos agentes tienen una meta muy precisa, anterior a cualquier tipo de acción. Su acción, en tanto paradigmas de legisladores (ideal, divino y real, o lo que es lo mismo, el teórico, el divino y el práctico), constituye el modelo más puro de praxis teórica: todo legislador debe tener presente la finalidad de su acción, la cual consiste en realizar un tipo específico de comunidad política que habrá de cobrar vida en cuanto dicha comunidad se dirija por las leyes que dictó. En sentido estricto, estos tres ejemplos de construcción nos conducen al paradigma de método cartesiano, pues lo que nos muestran es que ninguna obra moderna sería posible sin el camino que conduce a ella ni sin la finalidad inmutable, clara y distinta, que oriente a su creador a realizar cualquier acción. Así, podemos ahora responder, con algo más de conciencia, aquello sobre lo que basa Descartes la posibilidad de la nueva época (canceladora del azar, de las contingencias y de la casualidad). El fundamento de la nueva época es el método. Éste requiere, como en estos tres paradigmas, de una finalidad claramente definida y un camino que le acerque a ella, así como un único y solo constructor, si no divino, al menos prudente, pero sobre todo, real. Ahora bien, lo que en el discurso cartesiano está siendo sostenido sobre el nuevo método es la nueva ciencia y las resultas de ésta; veamos los dos últimos paradigmas cartesianos de construcción.

El sexto paradigma cartesiano de construcción es uno de los más importantes en la historia señalada por Descartes para desarrollar la nueva época; se trata de la ciencia. Como lo he señalado, los paradigmas de los legisladores dirigen la atención al paradigma del método. Esto no es fortuito pues, líneas más adelante, se exponen los — tan famosos como malentendidos - cuatro pasos del método cartesiano. También en la siguiente parte del Discurso del método se 
vuelve a poner en práctica lo que está pensando su autor respecto de la finalidad del proyecto cartesiano, el método mismo y la moral de provisión. El ejemplo cartesiano de la casa que se destruye "para edificar una nueva" (AT, VI: 22), etc., vuelve a recordarnos al primer paradigma cartesiano de construcción de nuestro esquema. No obstante, en este nuevo contexto, el sexto paradigma es, sin lugar a dudas, la piedra de toque para entender la finalidad de esta serie de paradigmas cartesianos de construcción, pues con él se desarrolla la meta del discurso cartesiano: el nuevo hombre. De acuerdo con el argumento cartesiano de la perfección de una obra basada en la autoría de un único constructor, las ciencias de los libros están muy lejos de detentar el verdadero conocimiento de las cosas. La formación de las ciencias está basada en la aglutinación de conocimientos diversos experimentados por diversos individuos. Sus conocimientos se ven engrosados de forma paulatina por las opiniones de diversas personas. Por lo tanto, tales conocimientos no son sino probables y carecen de demostración genuina; es decir, clara y distinta. En este sentido, las ciencias anteriores a la cartesiana no pueden estar tan cerca de la verdad como aquélla que sienta sus bases en los simples razonamientos que puede hacer de forma natural un hombre de bon sens (AT, VI: 12-13). ${ }^{6}$

${ }^{6}$ Esta indicación cartesiana parece poner en jaque la posibilidad del progreso de las ciencias, pues ¿cómo podrían explicarse los adelantos científicos sin las aportaciones críticas de quienes tratan de resolver problemas aparentemente insolubles desde la perspectiva inicial del desarrollo de una disciplina o de un sistema científico o filosófico? Para explicar el concepto de progreso científico tal como lo entienden los filósofos de la ciencia en su planteamiento original, sigo de cerca el argumento clásico de Kuhn (1986). Por otro lado, una excelente salida — tan coherente como iluminadora - respecto a la posibilidad del discrepar teórico sobre las posibles vías de reflexión ante un problema específico en cualquier disciplina de conocimiento, se encuentra en lo que Laura Benítez (2004) denomina las vías de reflexión filosófica —maravillosa veta ante las perplejidades inherentes a la búsqueda filosófica. 
Sin embargo, cabe resaltar que el argumento cartesiano no tiene qué ver de forma directa con el progreso de las ciencias, en plural, sino con la posibilidad de que ellas se acerquen a la verdad. De esto podemos distinguir dos cosas: primera, las ciencias de las que habla son obras que han sido compuestas y engrosadas paulatinamente por las opiniones de diversos hombres; por ello, muestran que no siguen el método que hemos develado en nuestro acercamiento a los tres tipos de legisladores, es decir, que no están sustentadas en una sola persona de bon sens, y por esta razón no pueden ser consideradas como ciencia. Segunda, el propósito explícito que aparece en el título completo del Discurso del método: pour bien conduire sa raison et chercher la vérité dans les sciences (AT, VI: 1), evidencia que el método cartesiano se dirige hacia la fundamentación de la verdad. Por ello, si el intento cartesiano consiste en conducir la razón y, por consiguiente, en buscar la verdad en las ciencias, su obra es el paradigma de construcción más elevado que pueda existir. Con él, todas las ciencias que se encuentren en la situación de buscar la verdad son organizadas sobre la base del método cartesiano; es decir, sobre la base metódica que hace posible a las verdaderas ciencias; base que, por cierto, su autor definió desde el postulado inicial del proyecto de la Modernidad. De acuerdo con lo que señala el fundador de esta nueva época, la ciencia verdadera no es la que se forma con opiniones de diversas personas, sino aquella que ha sido construida por un solo hombre de "buen sentido" tocante a las cosas que se le hacen presentes de manera evidente: Descartes habla de Descartes.

Por último, ¿qué consecuencia resulta de postular la importancia del constructor único - si no es que solipsista - a la hora de construir su obra en cada uno de los paradigmas cartesianos hasta llegar al de la única ciencia hecha por el más grande de los creadores, Descartes mismo? Esta pregunta encuentra su respuesta en el séptimo paradigma cartesiano de construcción: el nuevo hombre. De 
este modo, ya podemos enunciar la pregunta crucial de este trabajo: ¿En qué consiste el nuevo hombre cartesiano? Siguiendo el discurso del autor del Discurso del método encontramos una respuesta unívoca sobre lo que somos todos antes de ser hombres. Antes de ser hombres somos infantes. Esta consideración es importante porque con ella su autor nos coloca frente a las implicaciones directas de su proyecto. De lo que se trata, en pocas palabras, es de dejar de ser infantes. Descartes asume que aún los adultos que no se rigen por las leyes de la razón señaladas de forma discursiva por él, seguirán siendo infantes; esto es, dependientes de la tutela de los mayores. Nuestro Esquema B (ver infra, p. 173) es una imagen que intenta aclarar el proceso propuesto por Descartes para abandonar la infancia y pasar a la concreción del nuevo hombre.

En el desarrollo del proyecto cartesiano ser infante consiste, en resumen, en ser gobernado por nuestros apetitos y por nuestros deseos. El problema de ello es que con dificultad podemos encontrar consenso sobre lo óptimo para nuestra propia existencia, no se diga respecto de la búsqueda de la verdad. Además de esto, ser infante implica estar siempre bajo la tutela y cuidados de quienes en teoría estarían encargados de nuestra orientación. Esta orientación externa nos impediría hacer jamás un esfuerzo por ejercitar nuestra propia razón para dirigir nuestras acciones de manera autónoma y razonablemente justificada. Como puede verse, el estado infantil del hombre no es sustentable ante los embates del reino de la necesidad. Siguiendo el argumento ascendente de los paradigmas cartesianos de construcción, el estado infantil del hombre habrá de cancelarse cuando el nuevo hombre sea guiado siempre, desde el momento de su nacimiento, por la razón; es decir, cuando el nuevo hombre nazca racional. Pero ¿cómo es esto posible?, o más aún, ¿es posible?

$\mathrm{El}$ argumento cartesiano no carece de movimiento propio para responder a este problema y se sigue de la exhibición de los paradig- 
mas cartesianos que he presentado. Ya he hecho notar el movimiento ascendente de los siete paradigmas, también he intentado no descuidar la riqueza retórica del desarrollo argumental cartesiano, a saber, que de lo que se trata realmente en todo este pasaje es del único y solo constructor de la nueva época, Cartesio, creador absoluto. La ciencia verdadera es la que él enseña; con su discurso del método se cancelan los discursos aporéticos, confusos y falaces sobre la verdad (tan abundantes en la época que le tocó vivir). Descartes ha renacido como el hombre nuevo, como el hombre simplemente racional. A continuación trataré de explicar cómo es posible este movimiento al interior del Discurso cartesiano, o sea, cómo el hombre se convierte en el nuevo hombre y como éste construye su propio mundo; es decir, el mundo moderno.

El "primer ciclo de la construcción del mundo" cartesiano (recordar el movimiento del Esquema B) proviene de los paradigmas de construcción indicados en el Discurso del método. Siguiendo con puntualidad su presentación ascendente, el nuevo hombre aparece -en el relato de la creación cartesiana - tras las superaciones (análogas a las Aufhebungen hegelianas) que van desde el constructor solo de edificios hasta el hombre del proyecto moderno cartesiano; es decir, hasta el verdadero nuevo hombre, quien tiene la consigna de ya no gobernarse por sus apetitos, ni de ser esclavo de sus deseos, sino de dirigirse, desde su nacimiento, sólo por su razón. Para llegar a este estado (señalado en nuestros esquemas con el rectángulo número 7) es preciso haber dominado la naturaleza mediante el conocimiento científico que de ella este protonuevo hombre está adquiriendo con la praxis del método cartesiano (señalado en nuestros esquemas en el rectángulo número 6). Lo que le ofrece la oportunidad a ese protonuevo hombre de llegar a ser (y comprenderse como) un nuevo hombre es, en primer lugar, el dominio de la naturaleza y, después, el progreso del conocimiento a la luz del ejercicio de la nueva ciencia basada en 
aquél. La medicina, paradigma de ciencia moderna, con sus evidentes beneficios (progreso en el conocimiento y cancelación del dolor natural mediante el dominio y posesión de la naturaleza), deja de ser considerada como mera utopía y pasa a ser la abanderada y portavoz de la nueva época.

Por su parte, el "segundo ciclo de la construcción del mundo moderno" es una continuación mecánica del movimiento insoslayable del primer ciclo. Al haber realizado con éxito al nuevo hombre, implicado en el proyecto moderno cartesiano; es decir, a Descartes mismo, la universalización de esa comprensión conduce de forma necesaria a la concreción de la nueva época sustentada en la verdadera ciencia. El nuevo hombre no sólo produce al nuevo mundo (con la ayuda indispensable de la nueva ciencia, sustentada a su vez en el método inmanentista y solipsista) sino que, en principio, en el caso de Descartes, el nuevo hombre se produce a sí mismo. La primera diferencia radical entre el primer ciclo de la construcción del mundo y el segundo es que el hombre del primero construye edificios, mientras que el hombre (nuevo) del segundo es el constructor del hombre mismo y de su mundo. Con esto se hace evidente que el paradigma de este caso es Descartes, creador de sí y de una nueva época.

La segunda diferencia radical es la que se observa con la cancelación del paradigma de construcción de la verdadera religión ${ }^{7}$ en el segundo ciclo de la construcción del mundo moderno, pues si el nuevo hombre crea tanto al hombre moderno como a su mundo, el papel del Dios de la tradición imperante es obsoleto, lo cual es perfecta-

7 El desarrollo de esta postura se encuentra en la tercera parte del Discurso del método conocida en general como "algunos preceptos morales sacados de su método", en la cual algunos estudiosos han encontrado, con justicia, un argumento esotérico, permeado de términos bélicos, comunes en la época, sobre la moral de "aprovisionamiento"; es decir, provisional, mientras dura la guerra. Cfr. Keninngton (1987), Lachterman (1983) y Velasco (1995). 
mente compatible en la transición del primer ciclo al segundo ciclo de la construcción del mundo moderno con la caracterización cartesiana (tercera parte del Discurso del método) de la morale par provision. El primer momento del primer ciclo de la construcción del mundo moderno no detenta mayor complejidad ni mayor conocimiento; su principal tarea es mostrarnos la importancia del solipsismo para garantizar la perfección en la obra construida. En cambio, el primer momento del segundo ciclo está sustentado sobre la exacerbación y apoteosis del primer ciclo, a saber, el nuevo hombre que ha dominado su naturaleza (al controlar sus pasiones y deseos) y se guía por la sola razón. El primer momento de ambos ciclos es fundamental por ser el que comienza la realización del proyecto cartesiano en su específica determinación inmanentista. El primer momento del segundo ciclo de la construcción del mundo parte de una mayor complejidad y perfección, sustentada en la perfección del nuevo hombre que crea su nuevo mundo. Sin embargo, esta es la razón por la que en la historia del desarrollo del proyecto cartesiano el Dios de la tradición ya no puede entrar a escena en la comprensión del nuevo mundo, pues este personaje era el que jugaba el papel del creador en el mundo antiguo.

El hombre del proyecto moderno cartesiano del último momento del primer ciclo de la construcción del mundo moderno (señalado con el rectángulo 7) es en escencia diferente respecto del hombre análogo del segundo ciclo de la construcción del mundo moderno (señalado con el rectángulo 5 del ciclo superior). Esta diferencia se debe a las siguientes dos consideraciones: en primer lugar, el hombre del primer ciclo que construye edificios, ciudades y leyes es un hombre que todavía tiene como referente a Dios. Por consiguiente, en su relación con Él se manifiesta una dependencia que tiende a ser cada vez menor - hasta desaparecer por completo en el segundo ciclo. El menguar de esta dependencia del hombre hacia Dios está en proporción directa 
al incremento paulatino del uso de la razón. Esto es posible mediante la seria consideración y puesta en práctica del método propuesto por Descartes en todas y cada una de las cosas y creencias que constituyen al hombre y al mundo humano (indicado en nuestros esquemas con el rectángulo 6, "Ciencias"). Este paradigma de construcción es posible gracias a la realización del conocimiento verdadero que, dirigido por el método y la razón humana, hace posible la metamorfosis fundamental del proyecto cartesiano. Con este paradigma se garantiza que un hombre, tras un largo proceso inmanente, por fin deje de ser niño (es decir, que abandone la dependencia a las creencias adscritas al juicio de otros, sean éstos individuos, la tradición misma o supersticiones, miedos e ignorancia).

En segundo lugar, el matiz más importante en esta metamorfosis del hombre consiste en cancelar de manera radical el estado de dependencia tanto hacia los apetitos individuales como hacia los diferentes preceptores que hemos tenido. ${ }^{8}$ Todos ellos, apetitos y preceptores, son contrarios los unos a los otros. Sus contraposiciones no permiten que el hombre avance (progrese) hacia una meta bien (a través de la razón) dirigida. El último momento del primer ciclo de la construcción del mundo moderno, el hombre del proyecto moderno cartesiano, tiene las bases para dejar de ser niño y manifestar, mediante el ejercicio del método y la razón, su autonomía frente a las opiniones de los otros y su autarquía en lo concerniente a su acción en escencia productora. La caracterización esencial de esta toma de conciencia del nuevo hombre surgido del primer ciclo de la construcción del mundo moderno se pone de manifiesto, tan violenta como subrepticiamente, con la cancelación racional y metódica de lo que la tradición (supeditada en la opinión, el miedo, la superstición y la

${ }^{8}$ Cfr., el pasaje cartesiano en que muestra su "pensamiento" de que "todos nosotros hemos sido niños antes de ser hombres" porque la mayor parte de nuestra existencia "ha sido gobernada por nuestros apetitos y preceptores" (AT, VI: 13). 
ignorancia) había considerado era el principio de todo cuanto existe, incluyendo al hombre: con el advenimiento del nuevo hombre, Dios ha sido cancelado.

Una última consideración. Esta imagen de la cancelación de Dios está referida, en nuestra interpretación, únicamente al seguimiento del argumento cartesiano con el que se develaron los siete paradigmas de construcción con los que en el Discurso del método su autor hace posible el advenimiento del nuevo mundo. Su alcance, como resulta evidente, está limitado por el acercamiento que hemos intentado hacer respecto de la posibilidad de la nueva ciencia mediante el perfeccionamiento en el uso del método. La nueva ciencia, cartesiana, trae consigo el advenimiento del nuevo mundo. Para llegar a éste se requieren ciertos cambios específicos dirigidos por el movimiento del discurso cartesiano. Uno de esos cambios es el que se da con la diferencia del legislador ideal y el legislador real entre nuestra presentación del primer ciclo de la construcción del mundo moderno y la que se manifiesta en el segundo ciclo.

La diferencia entre el legislador ideal y el legislador real expuesta en nuestra presentación del primer ciclo de la construcción del mundo moderno tiende a desvanecerse en el segundo ciclo por la nueva acción del nuevo hombre. El nuevo hombre ya no es infante. Por lo tanto, dirige sus acciones por la razón - y sólo por esta facultad. El bon sens del nuevo hombre y la perfección en el ejercicio del método (presentado en la segunda parte del Discurso del método) le permiten al nuevo hombre romper sus ataduras de dependencia ante el cúmulo de pseudoconocimientos dirigidos por el caos de opiniones externas y veleidades internas, ahora superadas. El desvanecimiento de la diferencia entre el legislador real y el legislador ideal consiste en que el legislador ideal ya es real, es decir, que ya se trata de un legislador perfecto. Es el legislador que carece de errores en su cálculo al proponer leyes porque se guía por la sola razón y emplea el método cartesiano para encontrar la verdad. 
Lo que pretendo mostrar en lo que resta de este trabajo es que la acción del legislador perfecto y su realización efectiva no se puede concebir sino como el resultado necesario del proyecto inicial cartesiano. Para mostrar esta idea presentaré in extenso el pasaje cartesiano en el que fundamento mi comprensión central de los paradigmas de construcción moderna con la que me parece que se evidencia el movimiento necesario en lo que se refiere a la presentación, desarrollo y perfeccionamiento del legislador (paradigmas 3 a 5 [sic., 3, el legislador ideal; 4, el perfecto legislador, Dios y 5, el legislador real] del primer ciclo del proceso de construcción del mundo moderno de nuestro Esquema B, así como en su presentación modificada con los paradigmas 3.c [el legislador ideal] y 3.c' [el legislador real] del segundo ciclo del proceso de construcción del mundo moderno del mismo esquema). Vayamos, pues, a los textos cartesianos.

En lo que nombramos como paradigma 3 en el primer ciclo del proceso de construcción del mundo moderno, tenemos:

[Ainsi je mimaginai que] Del mismo modo yo me imagino que los pueblos, que antes habían sido semi-salvajes, y que habían llegado a ser civilizados paulatinamente no hacen leyes más que a la medida de la incomodidad que los crímenes y querellas lo exigían, no estaban tan bien civilizados como aquellos otros que desde su comienzo se organizaron en asambleas y decidieron observar las constituciones de algún prudente legislador.

En lo que se refiere al paradigma 4 del mismo proceso de construcción:

[Comme il est bien certain que] Como es bien cierto que el estado de la verdadera religión, de la cual Dios solo hace las ordenanzas, [éstas] deben ser incomparablemente mejor reguladas que todas las otras [leyes de las religiones]. 
Y, por último, en cuanto a lo que presentamos como paradigma 5:

[Et pour parler des choses humaines, je crois que] Y para hablar de cosas humanas, yo creo que, si Esparta en otro tiempo fue floreciente, no encuentra su causa en la bondad de cada una de sus leyes en particular, en vista de que algunas eran fuertes para extranjeros, y esas mismas contrarias a las buenas costumbres, pero por razón de que no fueron inventadas más que por uno solo, todas ellas tendían a una misma finalidad (AT, VI: 12).

En la medida en que este asunto trata sobre el problema del legislador, es evidente que se refiere a un tema fundamental de la filosofía política que no entra en los límites de este estudio, por lo que manifiesto que aunque soy consciente de él, me limitaré a presentarlo en los términos de mi interpretación sobre el proceso de la construcción del mundo moderno.

Descartes utiliza una diferencia estilística finísima que nos permite entender la diferencia entre los tres paradigmas de legisladores que nos está proponiendo. Podemos ver que la historia cartesiana del legislador ideal confrontado con el legislador real del que habla nuestro autor, y que nosotros presentamos en los pasajes centrales de nuestra interpretación del Esquema $\mathrm{B}$ del primer ciclo de la construcción del mundo moderno, es un relato que apela a la diferencia entre el legislador prudente que Cartesio se imagina y el legislador del que puede hablar para referirse a cosas humanas. Es decir, parece que la prudencia en el primer ciclo de la construcción del mundo moderno es una cosa divina, deseable pero no real. En términos cartesianos, el legislador prudente resulta ser un producto de la imaginación. Pero dado que el proyecto cartesiano es eminentemente autoproductivo, tiene que dejar el primer ciclo de la construcción del mundo moderno y pasar al segundo ciclo. En éste, gracias a la ciencia y al nuevo método - cultivados por el hombre de razón- el hombre que dicta leyes 
de acuerdo con un plan perfecto, ante todo, tiene que ser real. De esta manera, el legislador del segundo ciclo, debido a su autonomía y autarquía metódica-racional, no sólo es el legislador deseable, sino el único real. ${ }^{9}$ La diferencia entre el uso del entendimiento perfecto del legislador imaginado por Descartes (en el paradigma 3) y el uso del entendimiento perfecto práctico del legislador real del que Descartes puede hablar en términos humanos (en el paradigma 5) sustentado en el método y la razón se disuelve porque han llegado a ser lo mismo por el perfeccionamiento del uso del método en el segundo ciclo de

${ }^{9}$ El desarrollo cartesiano de estas ideas en su obra de 1637 puede seguirse con toda claridad y ejemplar dilección en su correspondencia con Elizabeth, especialmente en las cartas de Descartes del 21 de julio, del 4 y del 18 de agosto y en la del $1^{\circ}$ de septiembre de 1645. En esta serie de cartas, Descartes explica los medios que la filosofia enseña para conseguir la felicidad suprema que las almas vulgares esperan en vano de la fortuna aunque sólo podamos esperarla de nosotros mismos (AT, IV: 2513). Básicamente se centra en resaltar lo tratado por él en su Discurso del método, insistiendo en la idea que indica que en la medida en que el recto uso de la razón proporciona un conocimiento auténtico del bien, se impide con ese uso que la virtud sea errada, es decir, el desvanecimiento de la diferencia entre el legislador ideal y el legislador real. También, resalta la idea de que la mayor felicidad del hombre depende de ese recto uso de la razón y que, por consiguiente, el estudio, que nos lo proporciona, es la ocupación más útil, así como la más grata y deleitosa que pueda tener el hombre. Aunque todo esto tiene el tinte de una aproximación y análisis al texto de Séneca De beata vita, Descartes pone de manifiesto su postura (ligada directamente al nuevo método propuesto en su proyecto desarrollado perfectamente en su Discurso del método) cuando señala abiertamente el límite del filósofo cordobés, postulando simultáneamente su superioridad, a saber, que Séneca hubiera debido enseñarnos en su totalidad las principales verdades cuyo conocimiento es requisito para facilitar el uso de la virtud, regular nuestros deseos y pasiones y gozar asi de la beatitud natural (AT, IV: 267-8), cosas todas ellas que Descartes piensa que, no sólo sí mostró, sino que, además, logró -mediante su método y las implicaciones de su realización. Al respecto, cabe señalar que la idea que le parece más atinada del De beata vita es la que dice que beatus est qui nec cupit nec timet beneficio rationis (AT, IV: 274): feliz es el que gracias a la razón ni desea ni teme. 
la construcción del mundo moderno. Queda por ver, por supuesto, cómo es posible la cancelación de la diferencia entre teoría y práctica, adyacente en la identidad entre el legislador ideal y el legislador real en el nuevo mundo moderno, así como también, quién es capaz de sostener tal identidad; otra manera de presentar este problema es: ¿Cómo es posible y en qué consiste el nuevo hombre?, pero esto es tema para otro trabajo.

\section{Conclusión}

"El sentido original de la constructio cartesiana" es el título de este trabajo. En su desarrollo presenté cómo era entendido el concepto de construcción antes del advenimiento del nuevo sentido con el que Descartes inaugura la nueva manera de entender dicho concepto. Lo que se desprende de esta investigación es que antes de Descartes el término hacía referencia sólo al uso gramatical del concepto en cuestión y no tenía ninguna otra orientación importante. En cambio después de la publicación del Discurso del método, el sentido de la antigua constructio abandonó los horizontes gramaticales para abrir nuevos mundos. La importancia del sentido innovador cartesiano en lo que se refiere a la nueva comprensión del concepto radica en que el hombre es ahora el creador del nuevo mundo o, al menos, el creador de su propio mundo. El análisis de esta postura cartesiana en nuestro texto develó que el mundo es una construcción del hombre y con esta postura se enfatiza el carácter inmanentista del proyecto cartesiano. El problema más importante que surge de esta nueva manera de pensar al hombre y sus relaciones con el mundo, y con todo lo que le rodea, es que frente a la tradición, frente a las posturas antiguas o clásicas, el hombre comenzó a comprenderse a sí mismo como creador.

Esta oposición entre la comprensión del creador clásico y la nueva comprensión del constructor moderno sienta una de las bases más iluminadoras para entender la querella entre los antiguos y los 
modernos (herencia de la modernidad, por supuesto). El desarrollo de este estudio (mediante el análisis del proceso de los dos ciclos de la construcción del mundo moderno a la luz del estudio sobre los paradigmas de la construcción cartesiana) puso de manifiesto que uno de los problemas emergentes en esta contraposición entre el creador antiguo y el constructor moderno es el lugar que ocupa Dios en la nueva versión del mundo humano. Se indicó que el problema al que se apunta con ello es uno de los más grandes problemas de la filosofía política, a saber, la cuestión del problema teológico-político. Mi postura ante esta cuestión, aunque no justificada ni desarrollada en este trabajo, es que Descartes es perfectamente conciente del problema teológico-político, pero por razones prudenciales y prácticas decide no tratar estos asuntos del mundo (Cfr. Watson, 2007).

El dilema de la aceptación o el rechazo sobre la cuestión que se señala en el desarrollo de este trabajo acerca de si con el advenimiento del hombre moderno, derivado del proyecto original cartesiano, resulta que en efecto Dios es cancelado, habrá de ser una decisión de cada lector.

Por último, como nota aclaratoria, el sentido original de la constructio cartesiana tendría que entenderse de la siguiente manera: el nuevo sentido que le da Descartes a la noción de construcción es original en tanto que con ella nuestro autor origina a la nueva ciencia, al nuevo mundo, al nuevo hombre y, en suma, a la nueva vía de reflexión filosófica.

\section{Bibliografía}

Allighieri, Dante, 1987, Obras completas, Madrid, Biblioteca de Autores Cristianos, pp. 888.

AT: Descartes, René, 1996, Euvres Complètes, 11 vols., Adam, Charles y Paul Tannery (eds.), París, Librairie Philosophique J. Vrin. 
Benítez Grobet, Laura, 2004, Descartes y el conocimiento del mundo natural, México, Porrúa.

Cicero, Marcus Tullius, 1968, De Inventione, vol. II, trad. H. M. Hubbell, Londres, Loeb Classical Library.

, 1977, De Oratore, vol. IV, trad. H. Rackhmam, Londres, Loeb Classical Library.

, 1988, Brutus, vol. V, trad. W. Glynn Williams, Londres, Loeb Classical Library.

Cottingham, John, 1995, Descartes, coord. de la trad. Laura Benítez, México, UNAM.

Kennington, Richard, 1983, On Modern Origins. Essays in Early Modern Philosophy, Toronto, Lexington Books.

Klein, Jacob, 1992, Greek Mathematical Thought and the Origin of Algebra, Nueva York, Dover.

Kuhn, Thomas, 1986, La estructura de las revoluciones cientificas, México, FCE.

Lachterman, David Raport, 1983, "Descartes and the Philosophy of History", en Independent Journal of Philosophy, vol. IV, pp. 31-60.

, 1989, The Ethics of Geometry. A Genealogy of Modernity, Nueva York, Routledge.

Velasco Guzmán, Luis Antonio, 1995, "Modernidad y filosofía política en el Discurso del Método. Ensayo hermenéutico", en Antonio Marino (coord.), Inter Alia Hermeneutica. Memorias del Seminario de Hermenéutica y Ciencias del Espiritu, México, UNAM-FES-Acatlán, pp. 81-103.

Watson, Richard, 2007, Cogito, Ergo Sum. The Life of René Descartes, Boston, David R. Godine Publisher. 
Esquema A

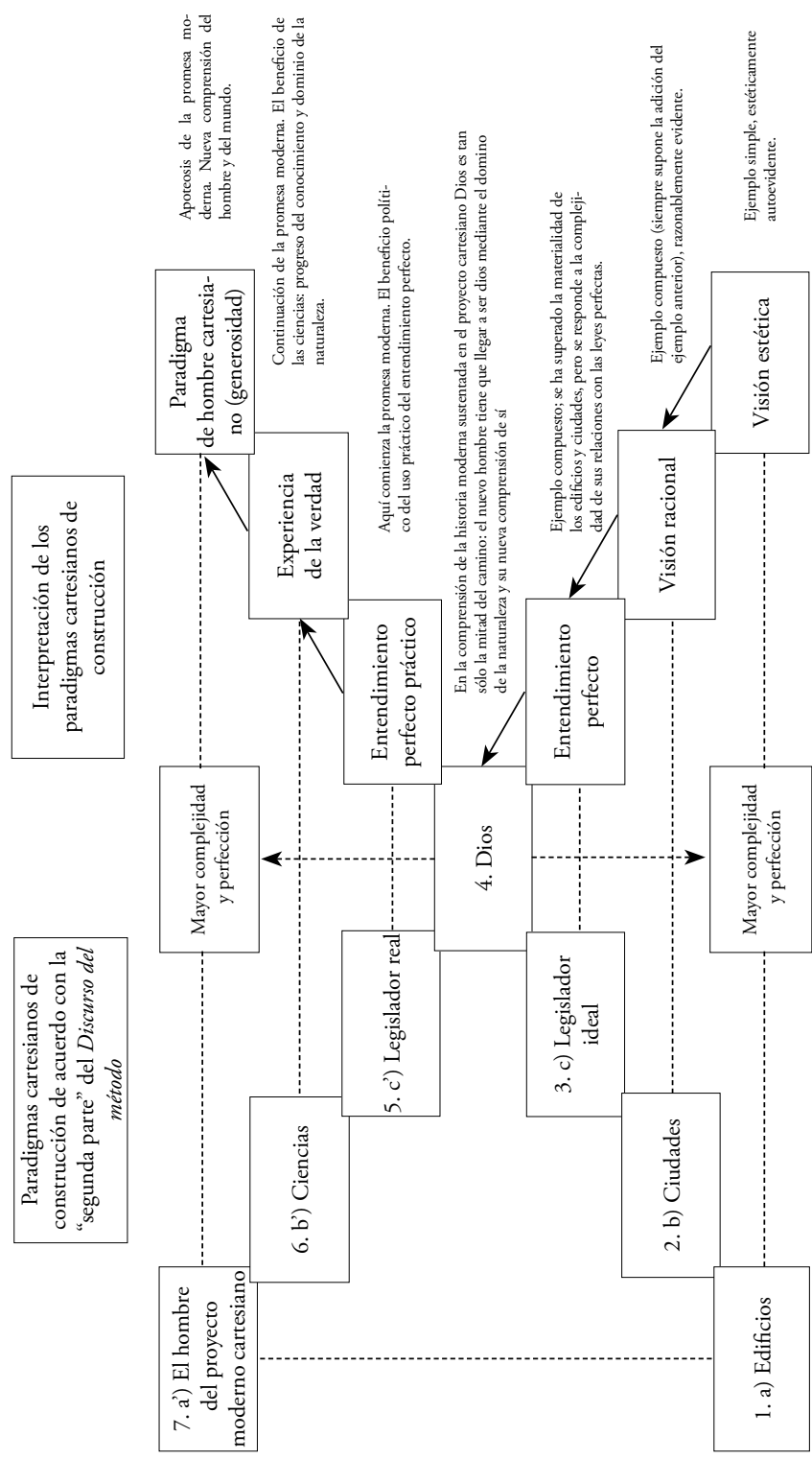




\section{Esquema B}

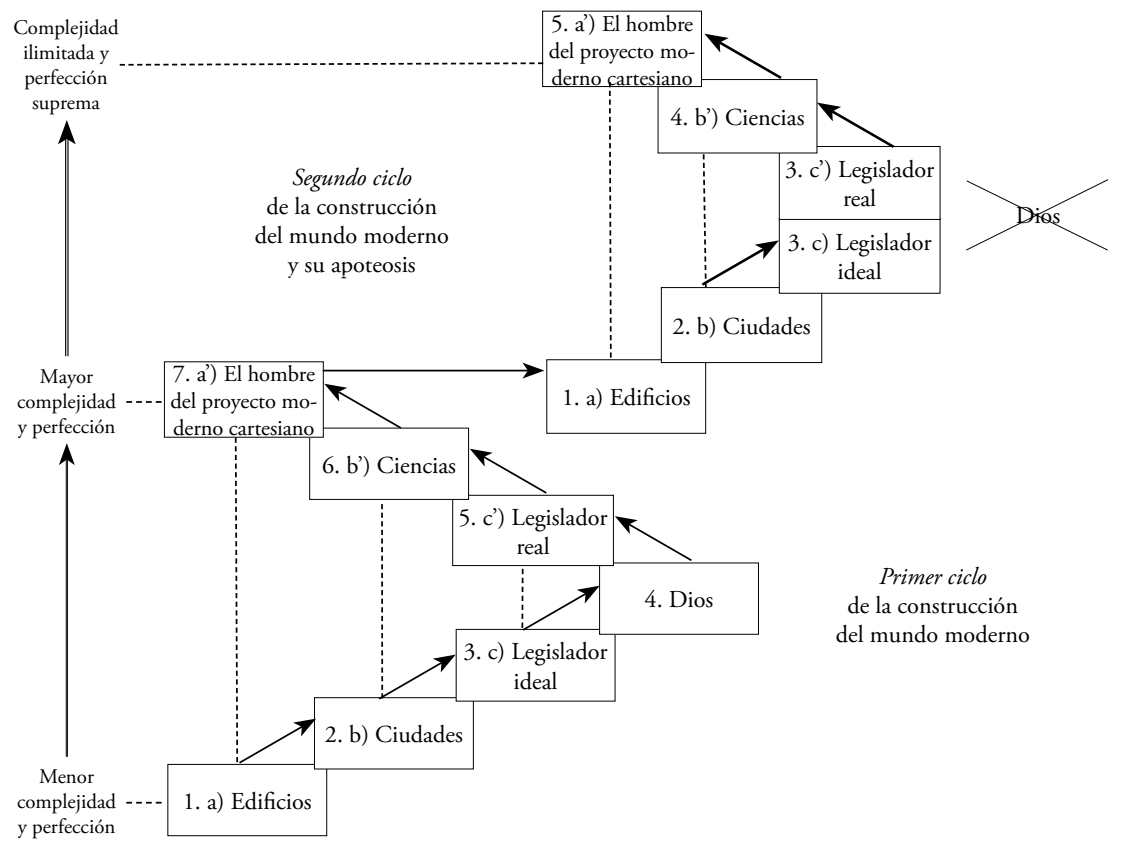

